\title{
Intensity-modulated stereotactic radiotherapy for the treatment of medically inoperable patients with NSCLC stage I
}

\author{
STEPHAN LÄCHELT ${ }^{1}$, MARKUS ALBER ${ }^{3}$, MATTHIAS SÖHN ${ }^{4}$, \\ MICHAEL BAMBERG $^{1}$, VOLKER STEGER ${ }^{2}$ and MARTIN WEINMANN ${ }^{1}$ \\ Departments of ${ }^{1}$ Radiation Oncology and ${ }^{2}$ Thoracic Surgery, University Hospital; ${ }^{3}$ Section of Biomedical Physics, \\ University Hospital of Radiation Oncology, D-72076 Tübingen; ${ }^{4}$ Section of Biomedical Physics, \\ University Hospital of Radiation Oncology, D-81377 Munich, Germany
}

Received May 31, 2012; Accepted July 3, 2012

DOI: $10.3892 /$ or.2012.1953

\begin{abstract}
The standard treatment for stage I non-small cell lung cancer (NSCLC) is lobectomy. However, a considerable number of patients are not eligible for standard lung surgery due to poor pulmonary function or comorbidities. We evaluated the efficacy and tolerability of intensitymodulated stereotactic radiotherapy (IMSRT) with moderate hypofractionation for these patients. Twelve patients were selected for IMSRT. 4D-CT planning was performed by gating CT-scanning positioning. The applied doses ranged between $10 \times 4.5$ Gy (80\% ID) $(\mathrm{N}=1), 12 \times 4.5$ Gy (95\% ID) $(\mathrm{N}=1)$ and $10 \times 5.5$ Gy (95\% ID) $(\mathrm{N}=10)$. Long-term follow-up was performed including spirometry and CT for evaluation of local, locoregional and distant control. Even in patients with poor pulmonary function IMRST was safe and well tolerated. No severe acute adverse effects were observed. Estimated local control at 2 years was $90 \%$. Moreover, IMSRT does not induce a significant deterioration of pulmonary function. IMRST is safe and feasible even for patients with very poor pulmonary function. The applied dose provides a high local control rate, although the biological equivalent dose (BED) is lower compared to the average of other SRT regimens. Therefore, IMRST may be an efficient alternative for all NSCLC stage I patients with contraindications to standard lobectomy especially in patients with small tumors in highrisk localisations.
\end{abstract}

\section{Introduction}

Lung cancer is the leading cause of cancer mortality in both men and women worldwide. Approximately $75 \%$ of patients

Correspondence to: Dr Martin Weinmann, Department of Radiation Oncology, University Hospital, Hoppe-Seyler-Str. 3, D-72076 Tübingen, Germany

E-mail: martin.bleif@med.uni-tuebingen.de

Key words: NSCLC stage I, stereotactic IMRT, pulmonary function with lung cancer are diagnosed with non-small cell lung cancer (NSCLC)-histology. Of these patients, 15-20\% are with NSCLC present with early-stage disease (stage I) which is defined by $\mathrm{T} 1$ or T2-tumors without evidence of loco-regional or distant metastasis. The number of patients diagnosed with stage I NSCLC is expected to rise over the next years due to the widespread use of screening for lung cancer with spiral computed tomography (CT).

The standard treatment for these patients is lobectomy. The standard surgery procedure in patients with stage I NSCLC has resulted in 5-year survival rates between $60-70 \%$ (1-3). However, there is a considerable number of stage I NSCLC patients who are not eligible for the standard surgical procedure due to poor pulmonary function or comorbidities $(4,5)$. More limited surgical approaches such as wedge resection can be offered to some of these patients, but they result in significantly higher rates of local recurrence and a poorer outcome (6)

Therefore, primary radiotherapy for early-stage NSCLC is considered an alternative for patients who cannot tolerate standard surgery. However, conventional radiotherapy is considered less effective compared to standard surgery with 5 -year survival rates in the range of $10-30 \%$ and local control rates are usually $<50 \%$ (7-13), when total doses between 60 and 66 Gy in 1.8- to 2.0-Gy fractions are applied. Several studies have reported that dose escalation might be beneficial, suggesting a dose-response relationship for local control in these patients $(14,15)$.

In the majority of the cases, early stage NSCLC is considered a localized disease. The rate of regional or distant failures is low (16) and survival is mainly limited by local control and comorbidity. In this cohort of patients higher local control could directly translate into an increased overall survival.

Therefore, a strategy which allows us to deliver high biological equivalent dose (BED) confined to the tumor region without compromising considerable parts of the surrounding lung tissue would be an ideal tool for the treatment of this group of patients. Stereotactic body radiation therapy (SBRT) enables us to limit the margin for setup errors by combining elements of highly conformal threedimensional radiotherapy with stereotactic targeting and the 
Table I. Patient characteristics.

\begin{tabular}{|c|c|c|c|c|c|c|c|c|}
\hline $\begin{array}{l}\text { Patient } \\
\text { no. }\end{array}$ & $\begin{array}{c}\text { Age } \\
\text { (years) }\end{array}$ & Gender & $\begin{array}{l}\text { Tumor } \\
\text { stage }\end{array}$ & $\begin{array}{c}\text { Tumor } \\
\text { localisation }\end{array}$ & $\begin{array}{l}\text { Fractionation } \\
\text { scheme }(\mathrm{Gy})\end{array}$ & $\begin{array}{l}\text { GTV } \\
\left(\mathrm{cm}^{3}\right)\end{array}$ & $\begin{array}{l}\text { ITV } \\
\left(\mathrm{cm}^{3}\right)\end{array}$ & $\begin{array}{l}\text { PTV } \\
\left(\mathrm{cm}^{3}\right)\end{array}$ \\
\hline 1 & 82 & M & cT1b cN0 cM0 & Segment 6 right & $10 \times 5.5$ & 14.5 & 34.5 & 46.5 \\
\hline 2 & 78 & $\mathrm{~F}$ & cT1a cN0 cM0 & Segment 2 right & $10 \times 4.5$ & 5.7 & 5.6 & 7.4 \\
\hline 3 & 63 & $\mathrm{~F}$ & cT1b cN0 cM0 & Segment 1 right & $10 \times 5.5$ & 2.6 & 3.1 & 6.1 \\
\hline 4 & 73 & M & cT1b cN0 cM0 & Segment $9 / 10$ right & $10 \times 5.5$ & 29.0 & 52.0 & 73.1 \\
\hline 5 & 67 & M & $\mathrm{cM} 1$ & Segment 6 right & $10 \times 5.5$ & 33.3 & 41.4 & 42.4 \\
\hline \multirow[t]{2}{*}{6} & 67 & $\mathrm{M}$ & cT3 cNo cM0 & Segment 6 left & $10 \times 5.5$ & 8.1 & 14.3 & 34.4 \\
\hline & & & & Segment 6 left & & 2.8 & 4.5 & 14.0 \\
\hline 7 & 76 & M & cT1a cN0 cM0 & Segment 10 left & $10 \times 5.5$ & 7.7 & 10.8 & 14.0 \\
\hline 8 & 83 & M & cT1b cN0 cM0 & Segment 3 right & $10 \times 5.5$ & 31.6 & 38.6 & 53.4 \\
\hline 9 & 66 & M & cT1b cN0 cM0 & Segment 6 right & $10 \times 5.5$ & 14.0 & 27.3 & 42.54 \\
\hline 10 & 77 & M & cT1a cN0 cM0 & Segment 3 right & $10 \times 5.5$ & 9.9 & 19.8 & 37.4 \\
\hline 11 & 72 & M & cT1a cN0 cM0 & Segment 1 left & $10 \times 5.5$ & 2.0 & 2.4 & 5.6 \\
\hline 12 & 64 & M & cT1b cN0 cM0 & Segment 2 right & $12 \times 4.5$ & 12.3 & 16.2 & 28.9 \\
\hline
\end{tabular}

F, female; M, male.

Table II. Pulmonary function before and after IMSRT.

\begin{tabular}{|c|c|c|c|c|c|c|}
\hline $\begin{array}{l}\text { Patient } \\
\text { no. }\end{array}$ & V5 (\%) & V20 (\%) & MLD & FEV1 pre-therapeutic (1) & FEV1 post-therapeutic (l) & FEV1post-/pre- (\%) \\
\hline 1 & 27.5 & 6.4 & 5.6 & 1.37 & 1.33 & 97.1 \\
\hline 2 & 7.9 & 1.6 & 2.0 & 1.52 & 1.53 & 100.7 \\
\hline 3 & 14.1 & 3.4 & 3.3 & 1.8 & 1.73 & 96.1 \\
\hline 4 & 18.0 & 6.2 & 4.3 & 1.9 & 1.8 & 94.7 \\
\hline 5 & 22.9 & 8.2 & 5.9 & 1.64 & 1.7 & 103.7 \\
\hline 6 & 27.5 & 6.9 & 5.8 & 1.32 & 1.39 & 105.3 \\
\hline 7 & 20.5 & 6.1 & 4.5 & 1.78 & 1.38 & 77.5 \\
\hline 8 & 19.3 & 7.0 & 4.7 & 1.6 & 1.32 & 82.5 \\
\hline 9 & 30.4 & 10.5 & 7.3 & 2.32 & 2.02 & 87.1 \\
\hline 10 & 13.2 & 5.9 & 3.7 & 2.96 & 2.89 & 97.6 \\
\hline 11 & 8.2 & 2.9 & 2.1 & 1.37 & 1.33 & 97.1 \\
\hline 12 & 16.6 & 4.1 & 3.2 & 0.97 & 1.0 & 103.1 \\
\hline
\end{tabular}

integration of a variety of strategies to include the effects of lung and other organ movement into the target volume concepts of treatment planning.

In this regard, SBRT enables a dramatic reduction of safety margins and a reduction of the treated volumes facilitating hypofractionation and escalation of BED.

Here we present the first results of a concept of intensitymodulated stereotactic radiotherapy (IMSRT) which integrates a LINAC-based hypofractionated frameless SBRT with IMRTplanning using a Monte Carlo (MC)-based algorithm for dose calculation and IGRT including daily control for setup errors with a cone beam CT in combination with a robotic couch. Special emphasis was placed on the evaluation of long-term pulmonary function.

\section{Patients and methods}

Patient population and characteristics. From March 2008 to February 2010, 11 patients with early stage lung cancer, one of them with two foci in the same bronchopulmonary segment, and one patient with a suspected solitary metastasis of a rectal cancer were treated by IMSRT. Tumor stage was classified according to the 6th edition of the UICC TNM Classification. Patient median age was 72 years (range, 63-83 years). The characteristics of the patients included in this study are provided in Table I.

Diagnostic and staging workup. The tumor sizes were determined by the volumetric measurement of the gross 
tumor volume on 4D-CT (see below), which had a range of $2.0-33.3 \mathrm{~cm}^{3}$, with a median volume of $9.9 \mathrm{~cm}^{3}$.

Staging was performed with integrated 18F-FDG Positron Emission Tomography/whole body computed tomography $(17,18)$. The diagnosis of NSCLC was confirmed by bronchoscopic or CT-guided biopsy in 10 of the 12 patients. A pulmonary function test, including the evaluation of pretreatment FEV1 was performed in all patients. Pre-treatment pulmonary function was evaluated by spirometry. The mean FEV1 was 1.62 l; range, 0.97-2.96 1. The details on pulmonary function before and after treatment are presented in Table II.

All patients were considered as medically and/or functionally inoperable due to poor pulmonary function or other comorbidities as assessed by the referring surgeon.

CT-planning for IMSRT. Respiratory-correlated CT (RCCT) datasets were acquired with a Siemens Sensation Open Scanner reconstructed with $1 \times 1 \times 3 \mathrm{~mm}^{3}$ voxel size. The CT datasets for each patient were grouped into eight CT sets $(0 / 25 / 50 / 75 \%$ inhale and 100/75/50/25\% exhale), where the $0 \%$ inhale CT was used as the planning geometry (19). Contours of the gross tumor volumes (GTVs) from all breathing phases as well as of the organs at risk (OARs) were defined and approved by a radiologist.

A clinical target volume (CTV) was generated to encompass GTVs of all breathing phases (CTVhull=ITV). The planning target volume (PTV) was defined as the internal target volume (ITV), expanded by $2 \mathrm{~mm}$ in order to account for setup uncertainties. This procedure resulted in PTVs between 5.6 and $73.1 \mathrm{~cm}^{3}$ (mean, $31.2 \mathrm{~cm}^{3}$ ).

Target volume definition and dose calculation for IMRT. For IMRT planning, the Hyperion planning software was used which allows constrained, equivalent uniform dose (EUD)based biologic optimization based on Monte Carlo dose distributions as previously described (20,21). In brief, Hyperion uses a two-stage IMRT optimization. The first stage optimizes the fluence map on the basis of a discretization into beamlets, whereby the beamlet dose calculation is performed by means of a dedicated pencil-beam algorithm with three-dimensional density corrections. For the second stage, the fluence distribution is segmented, and henceforth both segment weights and shapes are iteratively optimized according to MC-calculated segment doses. Dose-volume histograms were generated for PTV and CTV as well as for organs at risk. Example CT slices with dose distribution are provided in Fig. 1.

IMSRT. Patients were irradiated with frameless stereotactic body radiotherapy using a Synergy $S$ linear accelerator with built-in micro-MLC (Elekta, Sweden). Daily control for setup errors was performed with an integrated cone beam CT and positioning errors were corrected with a robotic couch by matching a slow free breathing CT-scan to the ITV contour. Ten to twelve daily fractions were applied in a period of two weeks up to an overall dose of 45-55 Gy (mean dose, 53.46 Gy) corresponding to BED doses in a range of 85 Gy based calculated by the Monte Carlo algorithm.

Follow up. The patients were controlled on a three-month schedule. Local and distant control was evaluated by contrast
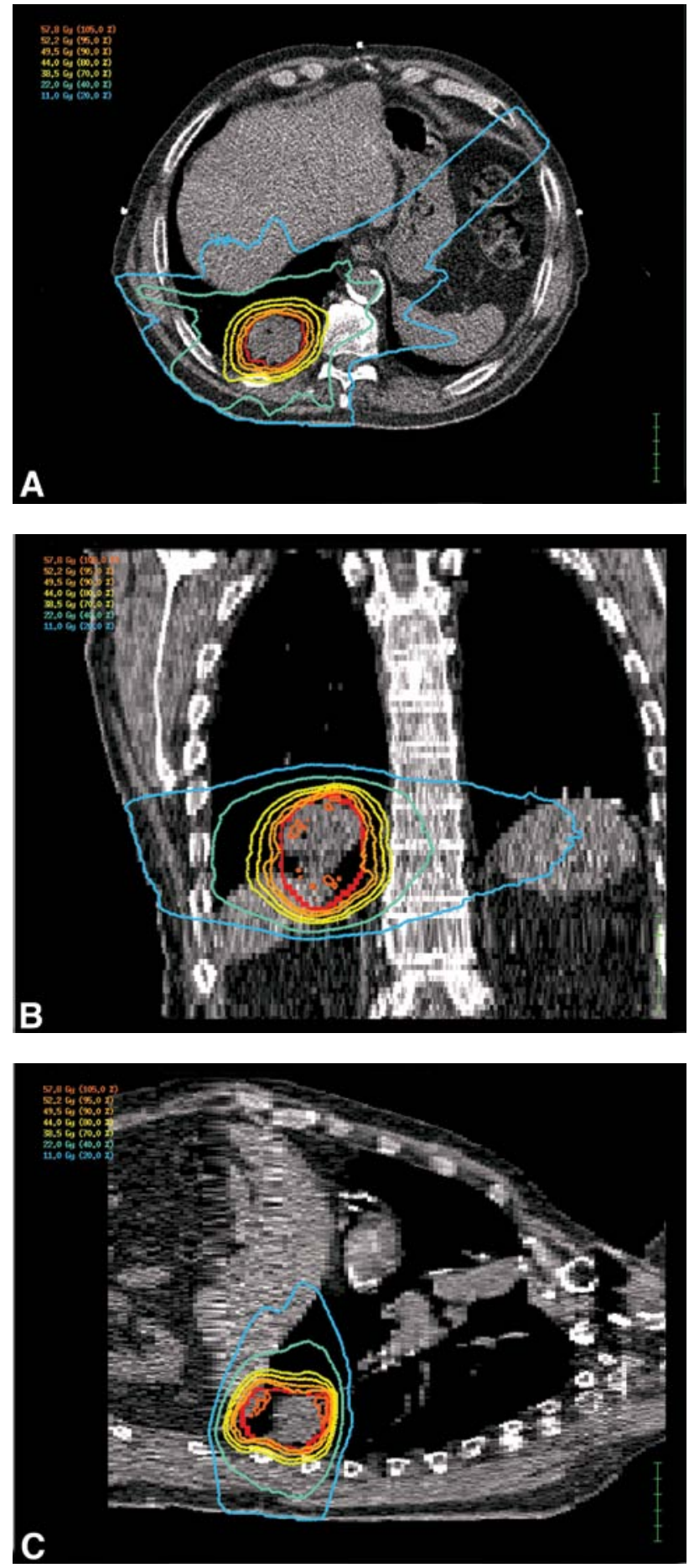

Figure 1. (A-C) Axial, coronar and sagittal example CT slices with dose contribution.

enhanced CT-scanning. Post-treatment pulmonary function was evaluated by spirometry.

Statistical analysis. Data analysis was performed using SPSS 18.0 statistical software. Estimated rate for local control (LC), disease-free survival; distant metastasis-free survival and overall survival were calculated according to the KaplanMeier method (22). Mean values for pre- and post-FEV1 were calculated and compared by the non-parametric Wilcoxon test (23) for paired samples. 

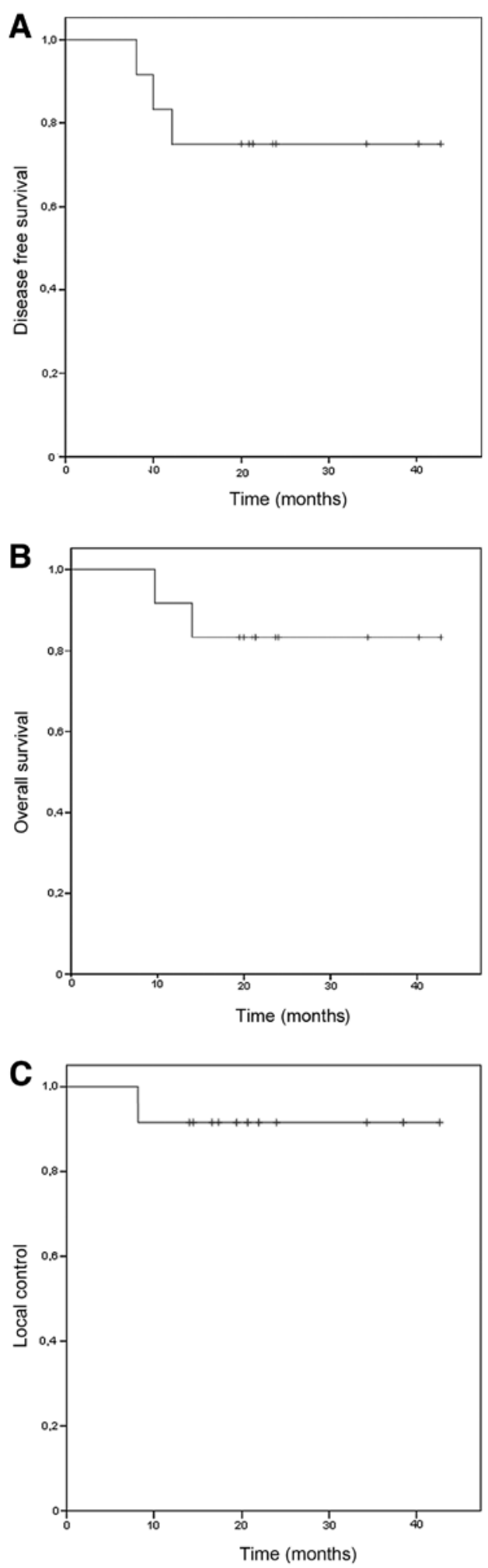

Figure 2. Kaplan-Meier plot for (A) disease-free survival, (B) overall survival and, (C) local control.

\section{Results}

Gross tumor volume, respiratory motion and size of ITV. The gross tumor volumes were defined on the basis of the lung gated $0 \%$ inhale CT. The volume of the GTV ranged between 2 and $33.3 \mathrm{~cm}^{3}$ (median, $9.9 \mathrm{~cm}^{3}$ ). The ITV volumes were in a range between 3.1 and $41.4 \mathrm{~cm}^{3}$ (median, $17.05 \mathrm{~cm}^{3}$ ), whereby the respiratory motion differed greatly between the various patients depending on the location of the tumor and the overall respiratory motion.

Local control, recurrence-free and overall survival. After a median follow-up period of 22.9 months (range, 9.6-42.7 months) 10 of the 12 patients were alive. Nine patients showed no evidence of progressive disease. The progression-free survival (PFS) was 85, 75 and $75 \%$ at 12, 24 and 36 months after therapy, respectively (Fig. 2A). The actuarial overall survival rates were 91,83 and $83 \%$ at 12,24 and 36 months after therapy, as calculated by the Kaplan-Maier method (Fig. 2B).

Local tumor recurrence was seen in only one of the 12 patients. This patient did not initially present with NSCLC, but with a suspected solitary metastasis of rectal cancer. At the time of local progress he also presented with synchronious lymph node and distant metastases. Two additional patients developed isolated distant failures 303 and 373 days after treatment. Calculated by the Kaplan-Meier method this resulted in actuarial local tumor control rates of 91 at 12, 24 and 36 months after therapy, respectively (Fig. 2C). None of the patients developed an isolated failure in the regional lymph node system.

Doses to normal tissue and treatment toxicity. The average mean lung dose in all patients was $4.4 \mathrm{~Gy}$ (range, 2-7.3 Gy), the V5 and V20 (24) were $18.65 \%$ (range, $7.9-30.4 \%$ ) and $6.15 \%$ (range, 1.6-10.5\%) (Table II).

The follow-up CT scans 3 months after treatment revealed discrete perifocal pulmonary tissue changes indicative of localized pulmonary fibrosis. However, these regions were confined to the vicinity of the initial tumor. These changes are indicative of subclinical regional pneumonitic changes and later fibroses. None of the patients developed clinical signs of acute or sub-acute pulmonary adverse effects like cough, dyspnoea or pneumonitis greater than CTC grade 2 .

The values for FEV1 prior to and 3 months following treatment are listed in Table II. In 3 of the 12 patients a deterioration of $>10 \%$ could be observed, however, there are no significant differences between the median of FEV1 pre-therapeutic and FEV1 post-therapeutic $[\mathrm{P}=0.059(>0,05)]$ analyzed by non-parametric Wilcoxon matched-pair signedrank test for related samples. These changes did not translate into apparent clinical worsening of respiratory symptoms in any patient.

None of the patients had chest wall pain requiring relief by analgetics or radiologic proof for rib fracture (25). No other late adverse events like pulmonary bleeding, osteoradionecrosis or myelopathy or cardiac adverse event were observed.

\section{Discussion}

Our results demonstrate that fractionated IMSRT is an effective and safe treatment even for stage I NSCLC patients with very poor pulmonary functions who are not suitable for standard surgical treatment. The local control rates are comparable with other concepts of SRT for NSCLC however the applied biological effective dose (BED) is in a range of $85 \mathrm{~Gy}$ and under the threshold of $100 \mathrm{~Gy}$, which has been proposed by numerous other authors (34). 
We consider IMRST as a favorable alternative in a cohort of patients who are not eligible for standard surgery. The local control rates achieved with IMSRT are comparable to surgical local control, but with lower complication rates.

Randomized comparisons of SRT and limited surgery are still pending (26), but the reported rates for local control are similar or even better in patients treated with SRT. In this regard, a recently published retrospective comparison of wedge resection $(\mathrm{N}=69)$ and image-guided lung SBRT reported a trend in local control in favor of SRT (27).

The efficacy of non-invasive treatment of NSCLC stage I by stereotactic radiotherapy has been demonstrated not only in our series but also by a rapidly increasing number of other phase II trials (28-33). However, a standard concept for dosage and fractionation of SRT in patients with stage I NSCLC based on these different trials has yet to be defined. A drawback for the establishment of a standard concept is that current trials exhibit a wide variety of different dose and fractionation concepts (single dose $30 \mathrm{~Gy}, 3 x 18-20 \mathrm{~Gy}, 5 x 8-10 \mathrm{~Gy}, 10 \times 5$ Gy prescribed to $50-95 \%$ isodoses). The majority of them achieve local control rates of $\geq 90 \%$, which is comparable to our study. The applied BED in our trial is lower compared to average of the other trials. Some authors described dose-effect relations in a range between BED of 80 Gy up to 100 Gy and recommend doses not below a BED of 100 Gy (34).

Therefore the question arises as to why our schedule seems to nevertheless be isoeffective compared to the data in the literature. There may be a variety of explanations. First, there are indications that BEDs $>80$ Gy add no additional benefit when small tumors with GTVs $<50 \mathrm{~cm}^{3}$ are treated (15).

Furthermore, most other trials used pencil-beam algorithms for dose calculation of SRT of lung tumors. In comparison to Monte Carlo optimized plans these pencil beam calculations overestimate the target doses in pulmonary tissue, whereas the doses to organs at risk do not differ accordingly $(35,36)$.

Since SRT is usually not prescribed according to the ICRU 50 guidelines for dose homogeneity, the doses within the PTV may reach peak doses higher than $100 \%$ of the prescribed dose. This makes the comparison of different dose concepts from different trials more complicated. In our study we prescribed 80 or $95 \%$ isodose, but peak doses up to $120 \%$ within the PTV were tolerated.

Also, local control is not only a function of the prescribed dose but also of the treatment accuracy and possible setup errors. The local control rate in this study is not inferior to the data in the literature, although not only the formal BED, but also the safety margin is smaller than in most other comparable studies. Therefore we performed daily matches of the cone beam CT to the ITV contour to ensure the correct coverage of the target volume. In addition, the ITV as defined in this study already has a type of internal safety margin around the GTV especially in the longitudinal extension due to the integration of all breathing phases. Perpendicular to the axial direction, the coplanar beam angles result in a slightly more spread conformal dose distribution (Fig. 1).

Collectively, this concept is not only efficient, but, due to the moderate BED and the small safety margins, it also seems especially suitable for tumors in high risk localisations. Since an increase of complication rates for centrally located tumors adjacent to large bronchi or vessels with dose concepts with extreme hypofractionation and BED >100 Gy has been described $(37,38)$, concepts with moderate hypofractionation and a BED $<100$ Gy may be appropriate for smaller tumors in unfavorable locations.

In conclusion, IMSRT is safe and feasible even for patients with very poor pulmonary function. The applied dose was able to provide a high local control rate in our cohort of patients. IMRST is an efficient alternative for all NSCLC stage I patients with contraindications to standard lobectomy. The optimal concept for dosage and fractionation remains to be determined.

\section{References}

1. Adebonojo SA, Bowser AN, Moritz DM and Corcoran PC: Impact of revised stage classification of lung cancer on survival: a military experience. Chest 115: 1507-1513, 1999.

2. Flehinger BJ,Kimmel M and Melamed MR: The effect of surgical treatment on survival from early lung cancer. Implications for screening. Chest 101: 1013-1018, 1992.

3. Naruke T, Goya T, Tsuchiya R and Suemasu K: The importance of surgery to non-small cell carcinoma of lung with mediastinal lymph node metastasis. Ann Thorac Surg 46: 603-610, 1988.

4. Allen MS, Darling GE, Pechet TT, Mitchell JD, Herndon JE II, Landreneau RJ, Inculet RI, Jones DR, Meyers BF, Harpole DH, et al: Morbidity and mortality of major pulmonary resections in patients with early-stage lung cancer: initial results of the randomized, prospective ACOSOG Z0030 trial. Ann Thorac Surg 81: 1013-1019, 2006

5. Birim O, Kappetein AP, Goorden T, van Klaveren RJ and Bogers AJ: Proper treatment selection may improve survival in patients with clinical early-stage nonsmall cell lung cancer. Ann Thorac Surg 80: 1021-1026, 2005.

6. Ginsberg RJ and Rubinstein LV: Randomized trial of lobectomy versus limited resection for T1 N0 non-small cell lung cancer. Lung Cancer Study Group. Ann Thorac Surg 60: 615-623, 1995.

7. Armstrong JG and Minsky BD: Radiation therapy for medically inoperable stage I and II non-small cell lung cancer. Cancer Treat Rev 16: 247-255, 1989.

8. Coy P, Hodson I, Payne DG, Evans WK, Feld R, MacDonald AS Osoba D and Pater JL: The effect of dose of thoracic irradiation on recurrence in patients with limited stage small cell lung cancer. Initial results of a Canadian Multicenter Randomized Trial. Int J Radiat Oncol Biol Phys 14: 219-226, 1988.

9. Dosoretz DE, Katin MJ, Blitzer PH, Rubenstein JH, Galmarini DH, Garton GR and Salenius SA: Medically inoperable lung carcinoma: the role of radiation therapy. Semin Radiat Oncol 6: 98-104, 1996

10. Haffty BG, Goldberg NB, Gerstley J, Fischer DB and Peschel RE: Results of radical radiation therapy in clinical stage I, technically operable non-small cell lung cancer. Int J Radiat Oncol Biol Phys 15: 69-73, 1988.

11. Kaskowitz L, Graham MV, Emami B, Halverson KJ and Rush C: Radiation therapy alone for stage I non-small cell lung cancer. Int J Radiat Oncol Biol Phys 27: 517-523, 1993.

12. Kong FM, Hayman JA, Griffith KA, Kalemkerian GP, Arenberg D, Lyons S, Turrisi A, Lichter A, Fraass B, Eisbruch A, et al: Final toxicity results of a radiation-dose escalation study in patients with non-small-cell lung cancer (NSCLC): predictors for radiation pneumonitis and fibrosis. Int J Radiat Oncol Biol Phys 65: 1075-1086, 2006.

13. Sibley GS, Jamieson TA, Marks LB, Anscher MS and Prosnitz LR: Radiotherapy alone for medically inoperable stage I non-smallcell lung cancer: the Duke experience. Int J Radiat Oncol Biol Phys 40: 149-154, 1998 .

14. Wurstbauer K, Weise H, Deutschmann H, Kopp P, Merz F, Studnicka M, Nairz O and Sedlmayer F: Non-small cell lung cancer in stages I-IIIB: long-term results of definitive radiotherapy with doses $\geq 80 \mathrm{~Gy}$ in standard fractionation. Strahlenther Onkol 186: 551-557, 2010.

15. Zhao L, West BT, Hayman JA, Lyons S, Cease K and Kong FM: High radiation dose may reduce the negative effect of large gross tumor volume in patients with medically inoperable early-stage non-small cell lung cancer. Int J Radiat Oncol Biol Phys 68: 103-110, 2007. 
16. Nath SK, Sandhu AP, Kim D, Bharne A, Nobiensky PD Lawson JD, Fuster M, Bazhenova L, Song WY and Mundt AJ: Locoregional and distant failure following image-guided stereotactic body radiation for early-stage primary lung cancer. Radiother Oncol 99: 12-17, 2011.

17. Detterbeck FC, Boffa DJ and Tanoue LT: The new lung cancer staging system. Chest 136: 260-271, 2009.

18. Lammering G, De Ruysscher D, van Baardwijk A, Baumert BG, Borger J, Lutgens L, van den Ende P, Ollers M and Lambin P: The use of FDG-PET to target tumors by radiotherapy. Strahlenther Onkol 186: 471-481, 2010.

19. Söhn M, Weinmann M and Alber M: Intensity-modulated radiotherapy optimization in a quasi-periodically deforming patient model. Int J Radiat Oncol Biol Phys 75: 906-914, 2009.

20. Alber M, Birkner M, Laub W and Nüsslin F: Hyperion: an integrated IMRT planning tool. In: Proceedings of the XIIIth International Conference on the Use of Computers in Radiation Therapy. Springer, Heidelberg, pp46-48, 2000.

21. Alber M and Nusslin F: Optimization of intensity modulated radiotherapy under constraints for static and dynamic MLC delivery. Phys Med Biol 46: 3229-3239, 2001.

22. Kaplan EL and Meier P: Nonparametric estimation from incomplete observations. J Amer Statist Assoc 53: 457-481, 1953.

23. Wilcoxon F: Individual comparisons by ranking methods. Biometrics Bulletin 1: 80-88, 1945.

24. Roeder F, Friedrich J, Timke C, Kappes J, Huber P, Krempien R, Debus $\mathbf{J}$ and Bischof $\mathrm{M}$ : Correlation of patient-related factors and dose-volume histogram parameters with the onset of radiation pneumonitis in patients with small cell lung cancer. Strahlenther Onkol 186: 149-156, 2010.

25. Andolino DL, Forquer JA, Henderson MA, Barriger RB, Shapiro RH, Brabham JG, Johnstone PA, Cardenes HR and Fakiris AJ: Chest wall toxicity after stereotactic body radiotherapy for malignant lesions of the lung and liver. Int J Radiat Oncol Biol Phys 80: 692-697, 2011.

26. Hurkmans CW, van Lieshout M, Schuring D, van Heumen MJ, Cuijpers JP, Lagerwaard FJ, Widder J, van der Heide UA and Senan S: Quality assurance of 4D-CT scan techniques in multicenter phase III trial of surgery versus stereotactic radiotherapy (radiosurgery or surgery for operable early stage (stage 1A) nonsmall-cell lung cancer [ROSEL] study). Int J Radiat Oncol Biol Phys 80: 918-927, 2011.

27. Grills IS, Mangona VS, Welsh R, Chmielewski G, McInerney E, Martin S, Wloch J, Ye H and Kestin LL: Outcomes after stereotactic lung radiotherapy or wedge resection for stage I nonsmall-cell lung cancer. J Clin Oncol 28: 928-935, 2010.

28. Bradley J, Graham MV, Winter K, Purdy JA, Komaki R, Roa WH, Ryu JK, Bosch W and Emami B: Toxicity and outcome results of RTOG 9311: a phase I-II dose-escalation study using threedimensional conformal radiotherapy in patients with inoperable non-small-cell lung carcinoma. Int J Radiat Oncol Biol Phys 61: 318-328, 2005.
29. Hof H, Herfarth KK, Münter M, Hoess A, Motsch J, Wannenmacher M and Debus JJ: Stereotactic single-dose radiotherapy of stage I non-small-cell lung cancer (NSCLC). Int J Radiat Oncol Biol Phys 56: 335-341, 2003.

30. Timmerman R, McGarry R, Yiannoutsos C, Papiez L, Tudor K, DeLuca J, Ewing M, Abdulrahman R, DesRosiers C, Williams M and Fletcher J: Excessive toxicity when treating central tumors in a phase II study of stereotactic body radiation therapy for medically inoperable early-stage lung cancer. J Clin Oncol 24: 4833-4839, 2006.

31. Wang L, Feigenberg S, Chen L, Pasklev K and Ma CC: Benefit of three-dimensional image-guided stereotactic localization in the hypofractionated treatment of lung cancer. Int J Radiat Oncol Biol Phys 66: 738-747, 2006.

32. Wulf J, Haedinger U, Oppitz U, Thiele W, Mueller G and Flentje M: Stereotactic radiotherapy for primary lung cancer and pulmonary metastases: a noninvasive treatment approach in medically inoperable patients. Int J Radiat Oncol Biol Phys 60: 186-196, 2004.

33. Xia T, Li H, Sun Q, Wang Y, Fan N, Yu Y, Li P and Chang JY: Promising clinical outcome of stereotactic body radiation therapy for patients with inoperable Stage I/II non-small-cell lung cancer. Int J Radiat Oncol Biol Phys 66: 117-125, 2006.

34. Guckenberger M, Wulf J, Mueller G, Krieger T, Baier K, Gabor M, Richter A, Wilbert J and Flentje M: Dose-response relationship for image-guided stereotactic body radiotherapy of pulmonary tumors: relevance of $4 \mathrm{D}$ dose calculation. Int J Radiat Oncol Biol Phys 74: 47-54, 2009.

35. Jelen U and Alber M: A finite size pencil beam algorithm for IMRT dose optimization: density corrections. Phys Med Biol 52: 617-633, 2007.

36. Sikora M, Muzik J, Söhn M, Weinmann M and Alber M: Monte Carlo vs. pencil beam based optimization of stereotactic lung IMRT. Radiat Oncol 4: 64, 2009.

37. Oshiro Y, Aruga T, Tsuboi K, Marino K, Hara R, Sanayama Y and Itami J: Stereotactic body radiotherapy for lung tumors at the pulmonary hilum. Strahlenther Onkol 186: 274-279, 2010.

38. Timmerman R, Paulus R, Galvin J, Michalski J, Straube W, Bradley J, Fakiris A, Bezjak A, Videtic G, Johnstone D, et al: Stereotactic body radiation therapy for inoperable early stage lung cancer. JAMA 303: 1070-1076, 2010. 